\title{
Book-Revieyt
}

\section{The Foundations of Immunology and Their Pertinence to Medicine}

\section{Mandakhnaran Davaadorj'}

'Department of Microbiology and Immunology, School of Bio-Medicine, Mongolian National University of Medical Sciences, Ulaanbaatar, Mongolia

\section{The Foundations}

of Immunology and their

Pertinence to Medicine

Peter Bretscher

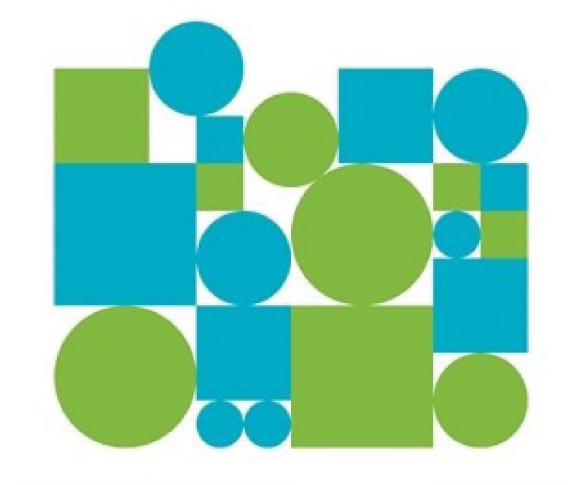

Editors: Joseph T DiPiro, Robert L Talbert, Gary C Yee, Gary R Matzke, Barbara $G$ Wells, and L Michael Posey.

Year: 2016

Publisher: Friesen Press

ISBN-10: $\quad 1460296559$

ISBN-13: 978-1460296554
This is an Open Access article distributed under the terms of the Creative Commons Attribution Non-Commercial License (http://creativecommons.org/icenses/bync/4.0/) which permits unrestricted non-commercial use, distribution, and reproduction in any medium, provided the original work is properly cited Copyright@ 2018 Mongolian National University of Medical sclences
A world-known immunologist who has been doing both conceptual and experimental immunology for nearly fifty years, Peter Bretscher has just written a wonderful book named "The foundation of immunology and their pertinence to medicine". Bretscher is widely recognized for the two-signal model of lymphocyte activation, which he published in 1970 together with Melvin Cohn. This model provided an explanation for how self/non-self-discrimination is realized by the immune system.

Chapter 1 describes the discovery of the immune system and how its attributes were recognized. It describes how vaccination against smallpox was already practiced with some success (but also lethality) in China and the Middle East before Edward Jenner established a safe protocol in the late 1700s. The chapter ends with a thought-provoking section on the discovery and importance of immune classes such as cell-mediated and humoral immunity, which are nowadays referred to as Th1 and Th2 immune responses. In the second chapter, the crucial role of the immune system in pathogenesis is demonstrated for at least five areas of medicine: autoimmune diseases, transplantation, infectious diseases, allergies and cancer. Chapters 3 and 4 are dedicated to the clonal selection theory of antibody formation which is a pillar of modern immunology. In Chapter 5, the significance of cellular cooperation in the generation of immune responses is explained. The development of Bretscher and Cohn's two-signal model for lymphocyte activation is described. Chapters 6 and 7 are dedicated to the roles of the molecules of the major histocompatibility complex and the function of antigen-presenting cells. In chapter 8, three competing models of peripheral tolerance of CD4 T cells are compared: Janeway's infectious non-self-model, Matzinger's danger model and Bretscher's two step, two-signal model. Understanding immune class regulation remains a key challenge in conceptual immunology and is the topic of chapters 9 and 10.

The book ends with a very stimulating 33 page chapter dedicated to novel strategies for medical interventions. Bretscher makes a number of 
concrete suggestions how conceptual immunology may be used clinically in domains as different as infectious diseases, allergy, autoimmunity, transplantation and cancer.

In conclusion, The Foundations of Immunology and their
Pertinence to Medicine clearly takes us on an extraordinary journey through the science of immunology from its very beginning through the most recent achievements with truly enlightening perspectives. 